Bayero Journal of Pure and Applied Sciences, 5(2): 128 - 131

Received: December 2012

Accepted: December 2012

ISSN $2006-6996$

\title{
EFFECT OF NAPHTHALENE ACETIC ACID (NAA) ON IN VITRO ROOTING OF REGENERATED MICROSHOOTS OF GROUNDNUT (ARACHIS HYPOGAEA L.)
}

\author{
*Abdulmalik, M.M., I.S.Usman, J.D. Olarewaju and D.A. Aba \\ Department of Plant Science, P.M.B 1044 Ahmadu Bello University Zaria, Nigeria. \\ *Corresponding author uwa6474@yahoo.com
}

\begin{abstract}
Successful utilization of tissue culture for the improvement and conservation of groundnut will be made possible only with an efficient shoot proliferation, formation of well-developed root system in microshoots, successful acclimatization and final establishment in field. A regeneration protocol ensuring a high frequency rooting of microshoots derived from embryonic axes of four groundnut genotypes was achieved using naphthalene acetic acid (NAA). Microshoots of $3 \mathrm{~cm}$ length were subcultured on Murashige and Skoog (MS) medium plus 30\% sucrose, supplement with 1.0 or $1.5 \mathrm{mg} / \mathrm{L} N A A$ and compared with a hormone free medium (control). Rooting was significant/y influenced by the presence and concentration of NAA. Microshoots subcultured in medium supplemented with $1 \mathrm{mg} / \mathrm{L}$ NAA rooted within 2 weeks of subcu/ture, producing the highest number of roots/plantlet and root-induction frequency. However, increasing the concentration of the auxin suppressed root length with the hormone free medium having the longest roots. Significant genotypic effect was also observed, with Samnut 22 having more number of roots/plantlet and root-induction frequency.
\end{abstract}

Key words: groundnut, microshoots, in vitro rooting, NAA

INTRODUCTION

The potential of tissue culture for conservation and genetic improvement of groundnut is well recognized (Gagliardi et al. 2002, 2003; Mckently et al. 1995; Swathi et al. 2006; Venkatachalam et al. 2000). However, successful utilization of tissue culture will be made possible only with an efficient shoot proliferation, formation of well developed root system in microshoots, successful acclimatization and final establishment in field. This under scores the need to established an efficient root induction protocol for successful field establishment. Mostly, in vitro rooting of microshoots has been achieved using media fortified with auxins either singly or in combination with cytokinins. Several rooting media have been employed to induce rooting in groundnut. Rooting was induced in groundnut on medium fortified with $2 \mathrm{mg} / \mathrm{L}$ NAA (Nazir et al. 2011) and a combination of indole butyric acid (IBA) and kinetin (KIN) (Venkatachalam and Jayabalan, 1997). While Gagliardi et al. (2000) were able to obtain rooting in groundnut on hormone free medium. Generally, groundnut response to tissue culture is strongly influenced by the plant genotype (Mroginsky et al.1981; Banerjee et al. 2007). Verma et al. (2009) were able to induce rooting in four genotypes of groundnut on MS medium fortified with $1 \mathrm{mg} / \mathrm{L}$ NAA, while a combination of $1 \mathrm{mg} / \mathrm{L}$ NAA and $0.5 \mathrm{mg} / \mathrm{L}$ IBA was required for rooting the fifth genotype.
In view of the genotypic influence in groundnut response to tissue culture, this study was carried with the objective of establishing an efficient root induction protocol applicable to a wide range of groundnut genotypes.

\section{MATERIALS AND METHODS}

Microshoots of $3 \mathrm{~cm}$ length (Figure 1) were subcultured on MS medium (Murashige and Skoog, 1962) plus $30 \%$ sucrose and supplement with 1.0 or $1.5 \mathrm{mg} / \mathrm{L}$ NAA and compared with a hormone free medium (control). The $\mathrm{pH}$ of the media was adjusted to 5.8 before autoclaving for $15 \mathrm{~min}$ at $121^{\circ} \mathrm{C}$. Ten test tubes were used per treatment and these were laid out in a completely randomized design replicated three times. Cultures were maintained in growth chamber at $26 \pm 2^{\circ} \mathrm{C}$ under $16 \mathrm{hr}$ light $/ 8 \mathrm{hr}$ dark photoperiod for five weeks. Well rooted plantlets were washed under running tap water to remove the medium from the roots. Root induction frequency, number of roots/plantlet and root length were taken for each treatment. Thereafter the plantlets were transferred to sterilized riverside sand and covered with transparent plastic bags to retain humidity and maintained at room temperature for 7 days before transferred to the screen house. Data collected were subjected to analysis of variance and means separated using DMRT. 


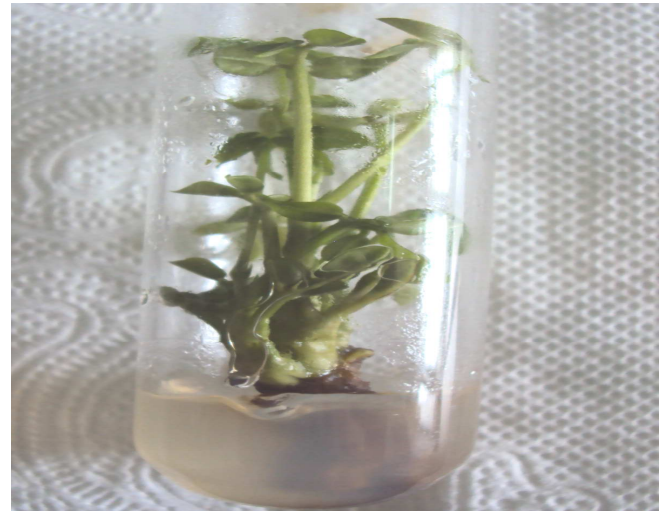

Figure 1: Regenerated microshoot of groundnut on MS medium $+15 \mathrm{mg} / \mathrm{L} \mathrm{BAP}$

\section{RESULTS AND DISCUSSION}

The presence and concentration of NAA significantly influenced rooting in groundnut. Rooting was observed within two weeks in responsive microshoots. Medium supplemented with $1 \mathrm{mg} / \mathrm{L}$ NAA recorded the highest root induction frequency $(82.42 \%)$ compared to $1.5 \mathrm{mg} / \mathrm{L}$ NAA treatment $(63.55 \%)$. Similarly, $1.5 \mathrm{mg} / \mathrm{L}$ NAA treatment produced higher root induction frequency compared to the hormone free medium (10.42\%) which recorded the least (Table 1 ). This result suggests that NAA is essential for high rooting frequency in groundnut microshoots as minimal rooting was observed in its absences. It has been established that auxin stimulates lateral root initiation by activating quiescent pericycle cells to initiate division and then expansion which facilitate lateral root emergence (Fukaki and Tasaka, 2009). Therefore appropriate synthesis, signaling and transport of auxin are all required for root formation (Peret et al., 2009). Root induction frequency obtained at $1 \mathrm{mg} / \mathrm{L}$ was higher than the frequency reported by McKently et al. (1990) at the same concentration. On the contrary, Gagliardi et al. (2000) reported high development of roots on MS hormone free medium.

The effect of NAA on number of roots/plantlet was significant. Medium supplemented with $1 \mathrm{mg} / \mathrm{L}$ NAA and $1.5 \mathrm{mg} / \mathrm{L}$ NAA produced comparable higher number of roots/plantlets (9.25 \& 9.42) compared to hormone free medium (Table 1; Figure 2). Auxin controls cell division, cell elongation and certain stages of differentiation (Davies, 2004) which could have increased the number of roots/plantlet. Lewis et al. (2011), reported that auxin increases the number of lateral roots. The value obtained in our study is higher than that reported by McKently et al. (1990) on basal medium supplemented with $1 \mathrm{mg} / \mathrm{L}$ NAA.

However, the presence and concentration of NAA in the medium decreased the root length. Hormone free medium produced the longest root length $(7.35 \mathrm{~cm})$ among the treatments (Table 1). Taiz and Zegler (2003) reported that although plants may require auxin for root induction but root growth is inhibited at higher concentration. Kollmeier et al. (2000) reported that root elongation phase is very sensitive to auxin concentration and it is inhibited by high concentration of auxin in the rooting medium. Auxin can increase the rate of ethylene biosynthesis (Riov and Yang, 1989). Therefore it could be possible that high concentration of NAA inhibited root elongation through the inducement of ethylene biosynthesis, which is inhibitory to root growth.

Significant difference $(P<0.05)$ was observed among the groundnut genotypes in response to the NAA treatment. Samnut 22 and Samnut 21 recorded the highest root induction frequency of 60.00 and $55.19 \%$ respectively, and were significantly higher than Samnut 23 and Samnut 10(Fig 3). Similarly, effect of NAA on number of roots per plantlets was significant, with Samnut 22, Samnut 23 and Samnut 21 producing more number of roots/plantlets than Samnut 10 (Fig 4). However, Samnut10 and Samnut21 produced the longest root lengths compare to the other genotypes (Fig 4). This result confirms earlier reports that rooting in groundnut is strongly influenced by the plant genotype (Venkatachalam and Jayabalan, 1997; Verma et al., 2009).

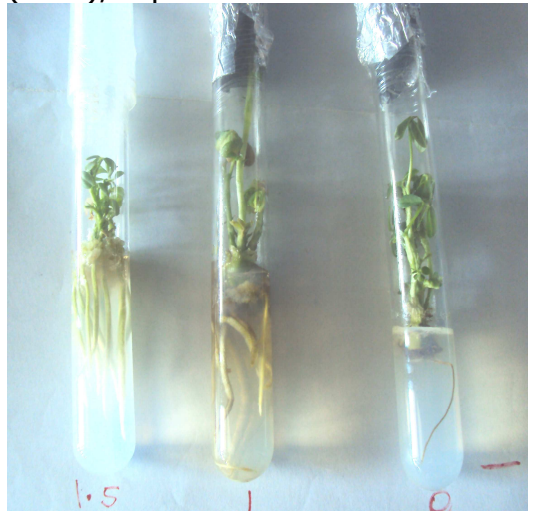

Fig 2: Plantlets after 4 weeks on rooting media (MS supplemented with $1.5,1 \mathrm{mg} / \mathrm{L} \mathrm{NAA}$ and control) 
Table 1. Effect of NAA concentration on in vitro root induction in groundnut.

\begin{tabular}{|l|l|l|l|}
\hline NAA concentration(mg/L) & Root induction frequency (\%) & No. roots/plantlet & Root length \\
\hline 0 & $10.42 \mathrm{c}$ & $1.67 \mathrm{~b}$ & $7.35 \mathrm{a}$ \\
1 & $82.42 \mathrm{a}$ & $9.25 \mathrm{a}$ & $5.30 \mathrm{~b}$ \\
1.5 & $63.55 \mathrm{~b}$ & $9.42 \mathrm{a}$ & $4.96 \mathrm{c}$ \\
$\mathrm{SE} \pm$ & 2.71 & 0.75 & 0.15 \\
$\mathrm{CV}(\%)$ & 12.72 & 26.94 & 6.36 \\
& & & \\
\hline
\end{tabular}

Means followed by the same letter(s) within a column are not significantly different using DMRT (*significant at $\mathrm{P}<0.05, * *$ highly significant at $\mathrm{P}<0.01)$.

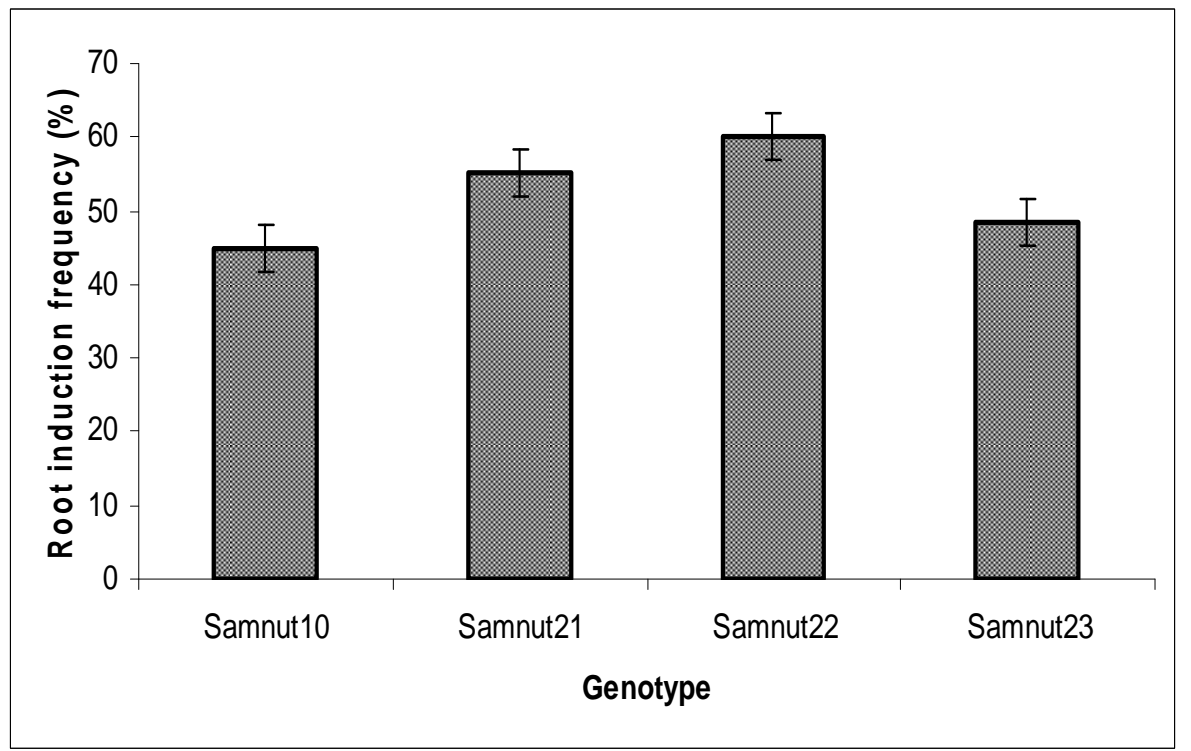

Fig 3: Root induction frequency (\%) of groundnut genotypes in response to NAA treatment.

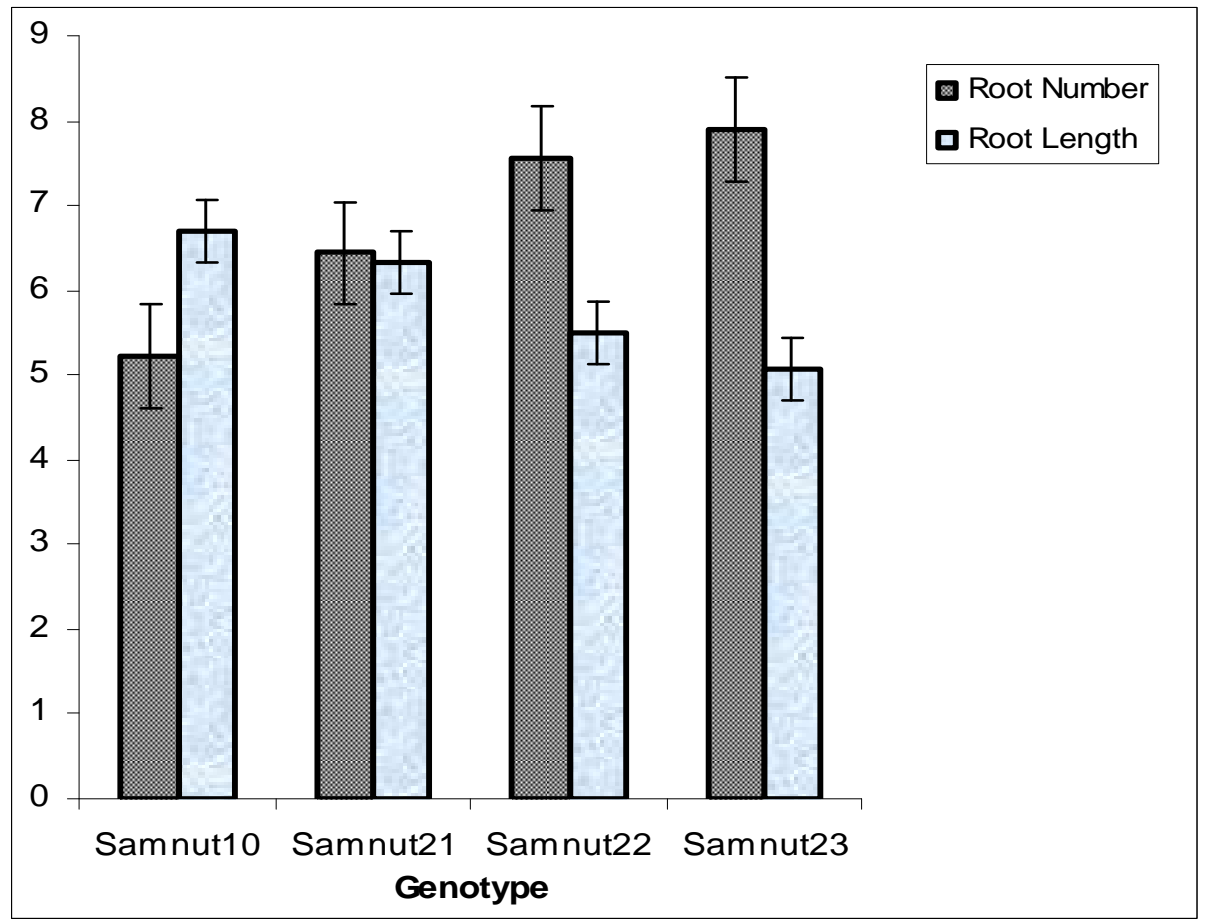

Fig 4: The root number and length in groundnut genotypes as influenced by NAA treatment.

\section{Conclusion}

Medium fortified with $1 \mathrm{mg} / \mathrm{L}$ NAA was found to be effective for root induction as it produced the highest root induction frequency and number of roots. While hormone free medium could be used for root elongation. The four groundnut genotypes evaluated responded well to the in vitro rooting by NAA. 


\section{REFERENCES}

Banerjee, P. Maity, S. Maiti, S.S., and Banerjee, N. (2007). Influence of genotype on in vitro multiplication potential of Arachis hypogaea L. Acta Bot. Croat. 66(1):15-23.

Davies, P.J. (2004). Plant hormones: Biosynthesis, Signal Transduction, Action! Dordrecht, Kluwer Academic Publishers, the Netherlands.

Fukaki, H. and Tasaka, M. (2009). Hormone interactions during lateral root formation. Plant Mol. Biol. 69, 437-449.

Gagliardi, R.F. Pacheco, G.P. Coculilo, S.P. Valls, J.F.M. and Mansur, E. (2000). In vitro plant regeneration from seed explants of wild groundnut species (Genus Arachis, Section Extranervosae). Biodiversity and Conservation. 9:943-951.

Gagliardi, R.F. Pacheco, G.P. Vall, J.F.M. and Mansur, E (2002). Cryopreservation of cultivated and wild Arachis species embryonic axes using desiccation and vitrification methods. Cryoletters. 23 (1):61-68.

Gagliardi, R.F. Pacheco, G.P. Carneiro, L.A. Vall, J.F.M. Vieira, M.L.C and Mansur, E. (2003). Cryopreservation of Arachis species by vitrification of in vitro-grown shoot apices and genetic stability of recovered plants. Cryoletters. 24(2):103-110.

Kollmeier, M. Felle, H.H and Horst, W.J. (2000). Is basipetal auxin flow involved in inhibition of root elongation. PI. Physiol. 122: 945-956.

Lewis, D.R. Negi, S. Sukumar, P. and Muday, G.K. (2011). Ethylene inhibits lateral root development, increases IAA transport and expression of PIN3 and PIN7 auxin efflux carriers. Development 138: 3485-3495.

McKently, A.H. Moore, G.A. and Gardner F.P. (1990). In vitro plant regeneration of peanut from seed explants. Crop Sci. 30:192-196.

McKently, A.H. Moore, G.A. Doostdar, H. and Niedz, R.P. (1995). Agrobacterium- mediated transformation of peanut (Arachis hypogaea L.) embryo axes and the development of transgenic plants. Plant Cell Rep. 14: 699703.

Murashige, T. and Skoog, F. (1962). A revised medium for rapid growth and bioassays with tobacco tissue cultures. Physiol. Plant. 15: 473-497.

Mroginsky, L.A. Kartha, K.K. and Shyluk, J.P. (1981). Regeneration of peanut (Arachis hypogaea) plantlets in vitro culture of immature leaves. Can .J. Bot. 59: 826-830.

Nazir, F. Hassan, M. Akram, Z. Javed, M.M. Ali, S. Ali, G.M and Zafar, Y. (2011). In vitro regeneration of Pakistani peanut (Arachis hypogaea L.) varieties using de-embryonated cotyledonary explants. African Journal of Biotechnology.10 (43): $\quad$ 8599-8604.

Peret, B. De Rybel, B. Casimiro, I. Benkova, E. Swarup, R. Laplaze, L. Beeckman, T. and Bennett, M. J. (2009). Arabidopsis lateral root development: an emerging story. Trends Plant Sci. 14, 399-408.

Riov J. and Yang, S. (1989). Ethylene and auxinethylene interaction in adventitious root formation in mung bean (Vigna radiata) cuttings. J Plant Grow Regu/8(2):131-141.

Swathi, T.A. Jami, S.K. Dalta, R.S. and Kirti, P.B. (2006). Genetic transformation of peanut (Arachis hypogaea L.) using cotyledonary node as explant and a promoterless gus::nptII fusion gene based vector. $J$. Biosci. 31(2): 235-246.

Taiz, L. and Zeiger, E. (2003). Auxins. In: Plant Physiology. Macmillan Publishing Co., New York 623pp.

Venkatachalam, P. Geetha, N. Abha, K. Shaila, M.S. and Sita, G.L. (2000). Agrobacteriummediated genetic transformation and regeneration of transgenic plants from cotyledon explants of groundnut via somatic embryogenesis. Curr. Sci. 78: 11301136.

Venkatachalam, P. and Jayabalan, N. (1997). Effect of auxins and cytokinins on efficient plant regeneration and multiple-shoot formation from cotyledons and cotyledonary-node explants of groundnut (Arachis hypogaea L.) by in vitro technology. Applied Biochem. Biotech. 67: 237-247.

Verma, A. Malik, C.P. Gupta, V.K. and Sinsinwar, Y.K. (2009). Response of groundnut varieties to plant growth regulator (BAP) to induce direct organogenesis. World J. Agric. Sci. 5(3):313-317. 